Pure Sciences

Poster

Abstract ID: 125

\title{
Persistence of chloramphenicol in the fish flesh patin (Pangasius Hypothalamus) and tilapia (Oreochromis Niloticus)
}

\author{
Jalal, K.C.A. ${ }^{a} \mid$ Helaluddin, A. B. M. ${ }^{b} \mid$ Akbar John, B ${ }^{a} \mid$ Mahbuba Bulbul ${ }^{c} \mid$ Nur Hafizah, M. N. ${ }^{a}$ \\ ${ }^{a}$ Kulliyyah of Science, International Islamic University Malaysia \\ ${ }^{b}$ Kulliyyah of Pharmacy, International Islamic University Malaysia \\ 'Institute of Tropical Aquaculture, Universiti Malaysia Terengganu
}

Introduction: Increasing antibiotic resistance in bacteria is a serious global problem. This study was aimed to extract the antibiotic Chloramphenicol (CAP) from different parts of the fish flesh. Methods: Fish fleshes were excised from two commercially important fishes: Oreochromatis niloticus.(Red Tilapia) and Pangasius hypothalamus (Patin). The fleshes were chosen form head and tail region where generally antibiotics are spiked to avoid bacterial contamination while kept in cold storages of supermarkets. Each fish fleshes were weighed and spiked with 20,40,80 and 160ppm of CAP and stored at $4^{\circ} \mathrm{C}$. The CAP residue from the flesh was extracted immediately after the first spiking was considered as Day-1. The whole extraction processes were done for 1,7,14 and 28 days. HPLC (High Performance Liquid Chromatography) was used to determine the presence of CAP residue in the tested fish flesh. Results: The results showed variations on the percentage of antibiotic residue recoveries at different concentration. In this study, CAP did not degrade and showed variations on the presence of antibiotic residue in the fish flesh. The recoveries of the entire CAP spiking samples ranged from $4.0 \%-100 \%$. It also revealed the presence of antibiotic residue in Malaysian freshwater cultured fishes. Thus, the relevant authorities should take immediate action regarding this issue in order to prevent the harmful effects especially to human. Conclusions: Nevertheless, the study portrays that antibiotic residues can be sustained long time in the food products under storage conditions, which might have harmful effects on human when they consumed these frozen fishes.

KEYWORDS: Antibiotic residue; Chloramphenicol (CAP); Patin; Tilapia; HPLC 